\title{
Invasive Molar Pregnancy in a Woman Aged 55 Years: A Case Report
}

\author{
M. Hristova ${ }^{1}$, S. Bozhilov ${ }^{1}$, N. Hristov ${ }^{1}$, Y. Tancheva ${ }^{1}$, N. Ivanova ${ }^{2}$, Mariana Penkova-Radicheva $^{2 *}$ \\ ${ }^{1}$ Department of Obstetrics and Gynecology, MHAT NiaMed, Stara Zagora, Bulgaria; ${ }^{2}$ Department of Internal Medicine, Medical \\ Faculty Trakia University, 11 Armeyska Street, 6000 Stara Zagora, Bulgaria
}

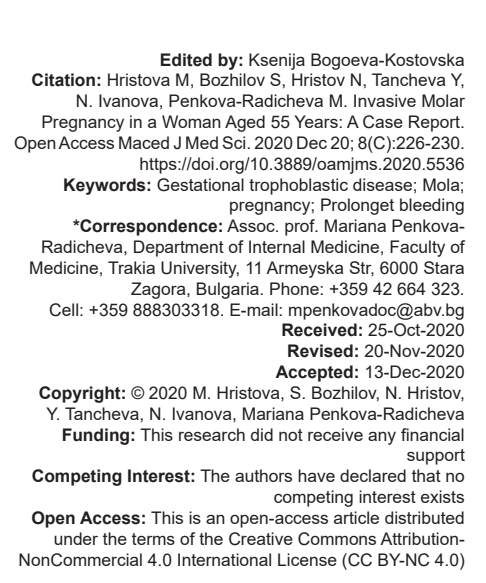

\section{Introduction}

Invasive mole is the penetration of molar tissue (complete or partial mole) into myometrium or uterine vasculature. Edematous villus and proliferative trophoblasts invade myometrium, so they can be distinguished from choriocarcinoma.

Human chorionic gonadotropin (HCG) level (>100000 $\mathrm{mlU} / \mathrm{ml}$ ), excessive uterine enlargement, and theca lutein cyst size $\geq 6 \mathrm{~cm}$ are considered as high risks for developing post-molar tumors (high-risk mole). The most common symptom of invasive mole is persistent vaginal bleeding after evacuation of molar pregnancy (sub-involution of uterus and persistent theca lutein cyst is another symptom). The rise in $\beta H C G$ titer is a laboratory test for diagnosis of an invasive mole in follow-up of molar pregnancy. Although definite diagnosis of invasive mole is based on pathology, with $\beta \mathrm{HCG}$ or radiologic diagnosis, invasive mole is diagnosed as well [1], [2], [3], [4], [5].

GTD describes a number of gynecologic tumors, which classification is as follows:

I. Premalignant form is representing:

1. Hydatidiform mole which is complete or partial.
II. Malignant:

1. Invasive mole

2. Choriocarcinoma

3. Placental site trophoblastic tumor

4. Epithelioid trophoblastic tumor.

Premalignant Malignant

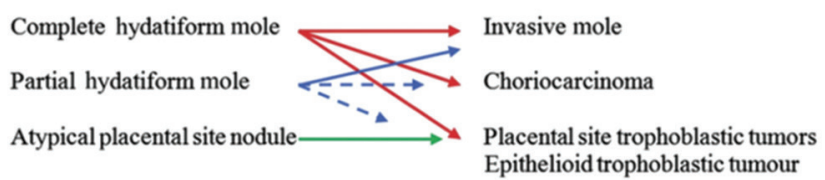

Invasive mole may arise from any pregnancy event, although in most cases, it is diagnosed after molar pregnancy. The invasive mole (chorioadenoma destruens) is a form of complete hydatidiform molar pregnancy evolution. Although this disease is characterized by an aggressive development that it is actually locally invasive, usually without distance dissemination, sometimes can also occur distant metastases. It is defined as a category of mole that penetrates and may even perforate the uterine wall. Rarely, it can spread to other organs, such as vagina, vulva, and lung. The invasive mole can be distinguished from choriocarcinoma by the presence of villi[7], [8]. The invasive mole classic describe macroscopic is 
characterized with trophoblastic invasion of myometrium with villous structures and microscopic is characterized by citotrofoblast hyperplasia, syncytial elements, and villous structures persistence. The invasive mole can be distinguished from choriocarcinoma by the presence of chorion villi[7], [10].

In rare cases, metastasis occurred and the most common sites were lungs (80\%), vagina $(30 \%)$, pelvis $(20 \%)$, liver $(10 \%)$, brain $(10 \%)$, and bowel and kidney and spleen ( $<5 \%$ ) which were other metastatic sites. However, metastasis to ovary from invasive mole is rare. About $5 \%$ to $6 \%$ of ovarian tumors come from metastasis of other organs. Metastasis can occur from direct extension of another pelvic neoplasm or by hematogenous or lymphatic spread or by transcoelomic dissemination. The possibility of metastasis to ovary is extremely rare which is even much lower than that of non-gestational primary ovary choriocarcinoma with an incidence of 1 in $3.7 \times 108$.

Ovarian non-gestational choriocarcinoma is a major differential diagnosis. Metastasis to the omentum is very rare in invasive mole. Invasive mole is curable with chemotherapy, but hysterectomy decreases the need for multiple courses of chemotherapy, and in patients with heavy bleeding or sepsis for control of complication and stabilization, chemotherapy is needed [1], [4], [6], [8], [10].

Here, we present a case with invasive mole with abnormal uterine bleeding (or dysfunctional uterine bleeding), low abdomen pain, and very increased thickness of the endometrium. Management and treatment with abdominal hysterectomy with bilateral salpingo-oophorectomy, in this case, was successful.

\section{Case Report}

A 55-year-old woman was admitted to MHAT NiaMed Ltd's Department of obstetrics and gynecology complaining of non-stop bleeding from the genital area for over one calendar month. Patient's history indicated by herself showed that she had been taking birth control pills until the age of 45 due to irregular menstrual cycle. First day of last regular menstrual cycle was in October 2019. The next month (November 2019) the cycle did not present. In December 2019, the cycle resumed for duration of 6 days, whereas on day 3 , the patient experienced two heavy hemorrhagic episodes. On day 7 , the hemorrhaging stopped, but on day 9, it resumed, although not as heavy as previously experienced and continued until the day of admission to MHAT NiaMed Ltd, namely, January 27, 2020.

On examination post-admission January 27, 2020 , the patient presents as a woman in good overall clinical health. On further gynecological examination, the uterus was discovered to be enlarged corresponding to
15-16 gestation weeks, with a soft texture and irregular form. The transvaginal sonography determined the following finding: Uterus with size 15-12-8 cm, with myoma located intramurally at the front uterine wall. The thickness of the endometrium was $44 \mathrm{~mm}$, presenting with non-homogenous grape-like characteristics and saturated blood supply. The right ovary - observed formation approximately $2.5 \mathrm{~cm}$ in size. The left ovary observed normal (Figure 1).

In terms of differential diagnosis, several diagnoses were discussed, such as benign and malignant pathology of the endometrium and ovaries. An X-ray examination of the lungs was performed, which did not show abnormal variations. Blood tests were conducted, showing results within the norm. On January 27, 2020, the patient was hospitalized. On the basis of the patient history as described above and the data gathered during the patient's examination, a decision was made to perform laparohysterectomy totalis cum adnexibus.

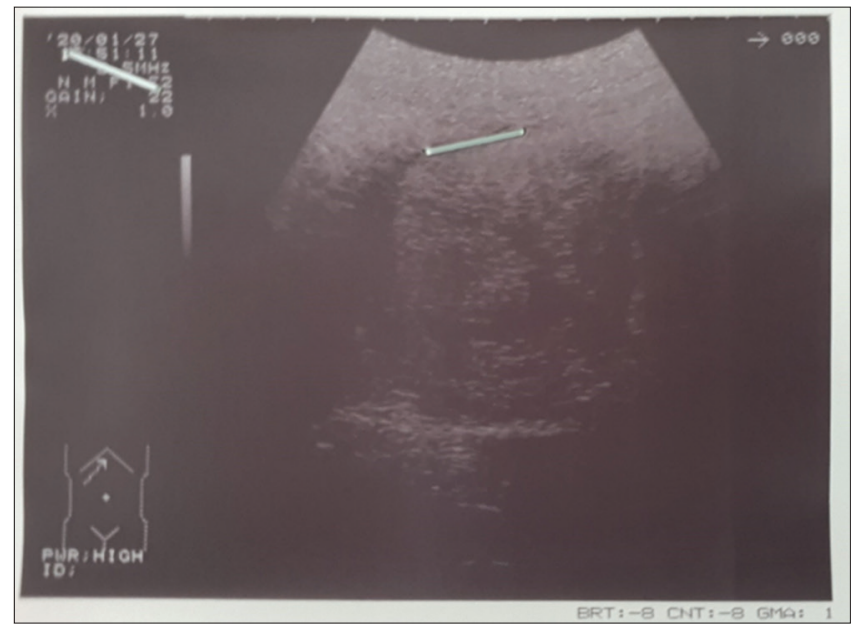

Figure 1: Transvaginal sonography

Blood analysis as hemoleucograma, coagulograma, liver enzymes, glucose, urea, and creatinine was within normal limits (Table 1). The chest X-ray was also a normal finding (Figure 2).

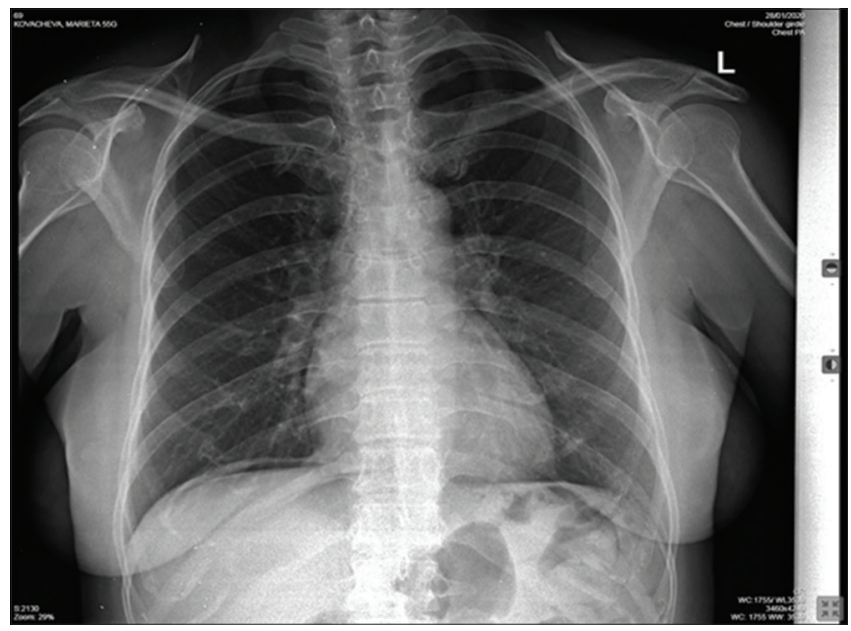

Figure 2: The chest $X$-ray

The abdominal wall was breached in the Pfannenstiel method. In situ findings: Uterus with size 
Table 1: Hemoleucogram, coagulogram, liver enzymes, glucose, urea, and creatinine

\begin{tabular}{lll}
\hline & Patient value & Normal range \\
\hline Blood & & \\
$\mathrm{Hb}$ & $112 \mathrm{~g} / \mathrm{L}$ & $120-160$ \\
$\mathrm{Ht}$ & $31.2 \%$ & $37.0-48.0$ \\
$\mathrm{Er}$ & $3.41 \times 10^{\wedge} 12 / \mathrm{L}$ & $4.20-5.60$ \\
$\mathrm{Leu}$ & $8.1 \times 10^{\wedge} \mathrm{g} / \mathrm{L}$ & $3.5-10.5$ \\
Lymph & $1.3 \times 10^{\wedge} 9 / \mathrm{L}$ & $08 .-4.0$ \\
Mid & $0.6 \times 10^{\wedge} 9 / \mathrm{L}$ & $01 .-0.9$ \\
Gran & $6.2 \times 10^{\wedge} 9 / \mathrm{L}$ & $2.0-7.0$ \\
Lymph & $16.3 \%$ & $20.0-40.0$ \\
Mid & $7.0 \%$ & $3.0-9.0$ \\
Gran & $76.7 \%$ & $50.0-70.0$ \\
MCV & $91.6 \mathrm{fl}$ & $82.0-95.0$ \\
MCH & $32.8 \mathrm{pg}$ & $27.0-33.0$ \\
MCHC & $358 \mathrm{~g} / / \mathrm{l}$ & $320-360$ \\
RDWCV & $13.6 \%$ & $11.5-14.5$ \\
RDWSD & $46.8 \mathrm{fl}$ & $35.0-56.0$ \\
PLT & $240 \times 10^{\wedge} 9 / \mathrm{L}$ & $140-440$ \\
MPV & $10.0 \mathrm{fl}$ & $7.0-11.0$ \\
PDW & 15.6 & $15.0-17.0$ \\
PCT & $0.240 \%$ & $0.108-0282$ \\
Prothrombin time & $11.8 \mathrm{~s}$ & Prothrombin time \\
Prothrombin activity & $119.1 \%$ & Prothrombin activity \\
INR & 0.85 & INR \\
Fibrinogen Quantity & $3.74 \mathrm{~g} / \mathrm{l}$ & Fibrinogen Quantity \\
Fibrinogen Time & $9.4 \mathrm{~s}$ & Fibrinogen Time \\
Urine & & \\
Protein & $(-)$ negative & Negative \\
Glucose & $(-)$ negative & Negative \\
Ketone & $(-)$ negative & Negative \\
Urobilinogen & $\mathrm{N}$ & Negative \\
Bilirubin & $(-)$ negative & Negative \\
Sediment analyses & $7-8 \mathrm{RBC}$ and BC on the field & Negative \\
\hline
\end{tabular}

corresponding to $15-16$ gestation weeks, right ovary corpus luteum $2.5 \mathrm{~cm}$ in diameter (Figure 3).

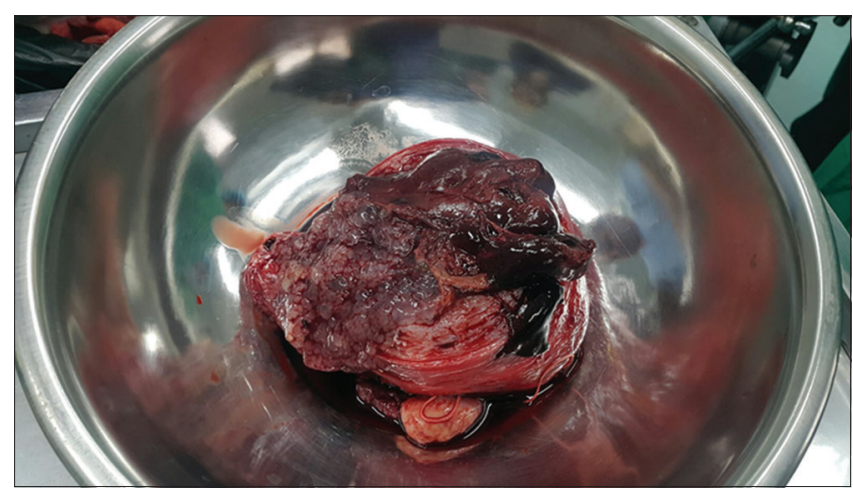

Figure 3: Macroscopic picture of the resected uterus

On slicing the uterus open, a tumor foundation was found with a spongy consistency and many grapelike spheres, some of which filled with clear liquid and some of which filled with rusty-brown liquid, ranging from $0.5 \mathrm{~mm}$ to $1 \mathrm{~cm}$ in size; heavy hemorrhaging and necrotic areas infiltrate that the myometrium was observed. After discussing the macroscopic view with a pathologist, a destructive mola was considered as a diagnosis; therefore, a blood sample for $\beta$-hCG was taken, with a result $26879 \mathrm{mlU} / \mathrm{L}$. The return of the histological samples from the operation showed the following results:

Macroscopic: Uterus enlarged by more than 15 $\mathrm{cm}$ in diameter. A tumor formation filling cavum uteri with spongy consistency formed by numerous grape-like spheres, some of which filled with clear liquid and some of which filled with rusty-brown liquid, ranging in size from several $\mathrm{mm}$ to $1 \mathrm{~cm}$. Abundance of hemorrhagic and necrotic sections with infiltration in the myometrium was found. Right ovary - corpus luteum $2.5 \mathrm{~cm}$ was in size.

The result obtained by the pathologists provided us with the following information:

\section{Macroscopic}

Enlarged uterus (more than $15 \mathrm{~cm}$ ) was found. A tumor formation, from the thicket of cavum uteri, with a soft consistency, built from a set of grape-like spheres, some of which filled with clear liquid and some of which filled with rusty-brown liquid, ranging in size from several $\mathrm{mm}$ to $1 \mathrm{~cm}$. Hemorrhages and necrotic areas, infiltration in the myometrium were discovered. The right ovary with a corpus luteum in size of $2.5 \mathrm{~cm}$ was found. (Figure 4).

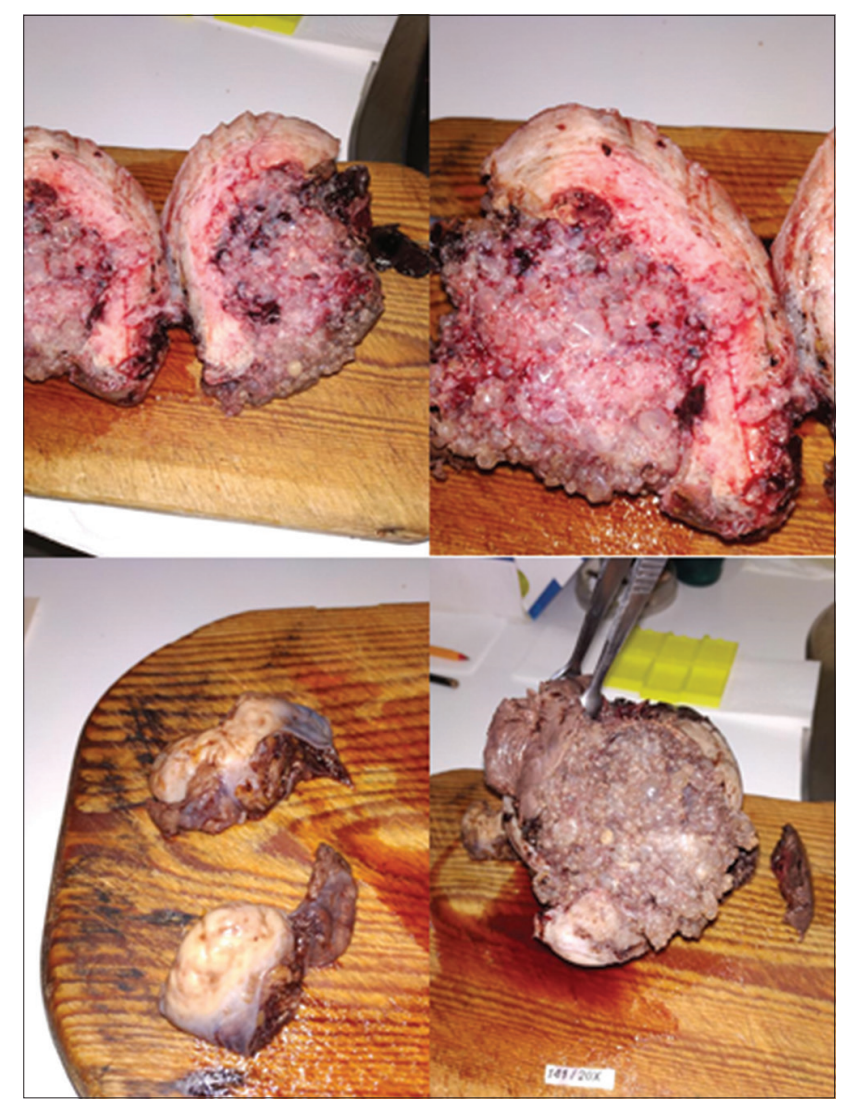

Figure 4: Sections of tumor formation

\section{Histologically}

1. Uterus: Tumor formation, built from highly dilated, edematous chorial villi with no blood vessels in them was found. Decidua and trophoblastic elements with moderate cellular and nuclear atypism, with extensive tumor necrosis and hemorrhage and penetration, covering about $1 / 3$ of the myometrium. The presence of single multi-core monstrous cell elements [Figures 5].

The find responds to invasive (destructive) mole hydatidosis FIGO I. 


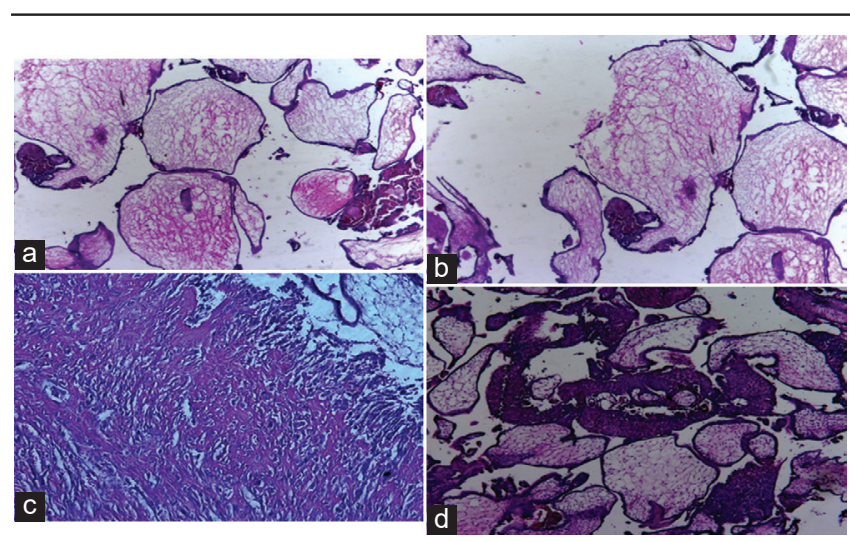

Figure 5: The presence of single multi-core monstrous cell elements

2. Cervix: Normal histological findings without abnormalities

3. Ovaries: Right ovary-corpus luteum, left ovary-normal histological findings without abnormalities

4. Fallopian tubes: Normal histological findings without abnormalities.

\begin{tabular}{ll}
\hline FIGO stage & Description \\
II & $\begin{array}{l}\text { Gestational trophoblastic tumors strictly confined to the uterine corpus } \\
\text { Gestational trophoblastic tumors extending to the adnexa or to the vagina } \\
\text { but limited to the genital structures }\end{array}$ \\
III & $\begin{array}{l}\text { Gestational trophoblastic tumors extending to the lungs, with or without } \\
\text { genital tract involvement } \\
\text { All other metastatic sites }\end{array}$ \\
IV & Al
\end{tabular}

There were no pre-, intra-, and post-operative complications.

The blood result of beta HCG after 10 days was $878.79 \mathrm{mlU} / \mathrm{ml}$ (Table 2).

Table 2: Beta HCG in blood

\begin{tabular}{lllll}
\hline Hormone & $30.01 .2020 \mathrm{y}$ & $10.02 .2020 \mathrm{y}$ & $02.03 .2020 \mathrm{y}$. & $07.04 .2020 \mathrm{y}$ \\
\hline$\beta$-human chorionic & $26879 \mathrm{mlU} / \mathrm{L}$ & $878.79 \mathrm{mIU} / \mathrm{L}$ & $111.34 \mathrm{mlU} / \mathrm{L}$ & $47.41 \mathrm{mlU} / \mathrm{L}$
\end{tabular}
-human chorion
gonadotropin

The patient was sent to an oncological committee for discussion whether subsequent chemotherapy is needed. The decision of the oncological committee was a follow-up with a re-review of histological slides, control on beta-HCG in 3 weeks (Table 2) and control computed tomography (CT) scan.

The re-review of histological slides shows: Cervix - normal histological findings without abnormalities; uterus - invasive (destructive) mole hydatidosis; and ovaries and fallopian tubes - normal histological findings without abnormalities.

Control CT scan shows normal anatomical findings after hysterectomy, without CT data for active the underlying disease. According to RECIST criteria - complete response was achieved [5], [7], [8], [9].

The patient's condition in the late post-operative period was good without any data on subsequent general and gynecological complications.

\section{Discussion}

Gestational trophoblastic disease (GTD) is class of tumors characterized by an abnormal proliferation of trophoblast. It is known that the appearance of pregnancy in perimenopause period is extremely low, rare, and unique. There are a number of factors that make both conception and a healthy pregnancy harder for older women. First in this woman in perimenopause, the ovulation becomes irregular, making conception more difficult. In other sites, men are constantly producing new sperm, but women are born with all eggs reserve. By the time four decades have passed, those eggs have aged and increasing the chance of chromosomal abnormalities. Teenagers and perimenopause women are most affected by GTD. All women of reproductive age may potentially develop a GTD. This is the reason why histopathological analysis is necessary to exclude trophoblastic disease in all cases that are clinically indicated or not. Even more, suspicion should be high and should exclude the disease of a product of conception derived from miscarriages, in patients at extreme age. It was assumed that our patient is in perimenopause period (no hormonal investigations were carried for this diagnosis) with dysfunctional (abnormal) uterine bleeding [3]. The first diagnosis considered was dysfunctional (abnormal) uterine bleeding (due to the height of the endometrium and the inability to desquamate and evacuate on its own, due to the hormonal deficiency that occurred during this period of the woman's development) and fibroid uterus. Any other causes of endometrial bleeding also were considered: Endometrial or ovarian malignancies or benign injury. A trophoblastic disease was not estimated in this case, and due to that $\beta$-hCG measurement was not performed initially. Most women will only need a minor surgery for a trophoblastic disease (biopsy curettage), to remove the molar tissue. However, a small percentage of this will need chemotherapy. In case of our patient, it was decided that a hysterectomy should be performed. No residual trophoblastic disease was found after the surgical treatment, and references of the $\beta$-hCG levels remain undetectable.

\section{Conclusion}

The number of pregnancy in perimenopause period is very low. The incidence of molar pregnancy increases at the extremes of reproductive age, teenagers, and perimenopause women. With this 
case that we have chosen, we want to emphasize that this condition can occur in relatively advanced age, especially during perimenopause period. Examining the tissue after a miscarriage in women at extreme ages should raise a suspicion of mole. Molar pregnancy should be excluded in these cases.

\section{References}

1. Gary CF. Williams obstetrics. In: Gestational Trophoblastic Disease. 24th ed., Ch. 20. New York: McGraw-Hill Education; 2014. p. 396-404.

2. Oikonomidis P, Pergialiotis B, Pitsouni E, Natsis S, Lagkadas A Giannakopoulos K. Repetitive complete molar pregnancy in a 54-year-old patient in a time distance of eighteen years from the first incident: Case report and mini review. Case Rep Med. 2011;2011:351267. https://doi.org/10.1155/2011/351267 PMid:22110509

3. Available from: https://www.ajog.org. [Last accessed on 2020 May 20].

4. Palmer JR. Advances in the epidemiology of gestational trophoblastic disease. J Reprod Med. 1994;39(3):155-62. PMid:8035370

5. Aminimoghaddam S, Maghsoudnia A. Unusual presentation of invasive mole: A case report. J Reprod Infertil. 2017;18(1):205-9. PMid:28377901

6. Leocadio CM, Villayzán JG, López JG, Idrovo F, Arranz JP, González MA. Invasive mole in a perimenopausal woman with lung and vaginal metastases: A case report. Clin Case Rep. 2019;7(12):2300-5. https://doi.org/10.1002/ccr3.2386 PMid:31893046

7. Ionescu CA, Bragaru M, Tarcomnicu IM, Vladescu CT, Dimitriu M. Invasive molar pregnancy in a woman aged 54 years a case report. J Clin Case Rep 2016;6:3. https://doi. org/10.4172/2165-7920.1000733

8. El-Agwany AS, Abdeldayem TM. Invasive mole of the uterus: A description of two cases managed by hysterectomy. Egypt J Radiol Nucl Med 2015;46:1267-70. https://doi.org/10.1016/j. ejrnm.2015.06.017

9. Chalian H, Töre HG, Horowitz JM, Salem R, Miller FH, Yaghmai $V$. Radiologic assessment of response to therapy: comparison of RECIST versions 1.1 and 1.0. Radiographics. 2011;31(7):2093-105.

10. Ngan HY, Bender H, Benedet JL, Jones H, Montruccoli GC, Pecorelli S, et al. Gestational trophoblastic neoplasia, FIGO 2000 staging and classification. Int J Gynecol Obstet. 2003;83:175-7. 